\title{
Prevalence of Oral Anomalies and Pathologies in the Pakistani Population - A Cross Sectional Study
}

\author{
Ambreen Shahzad ${ }^{1}$ \\ Amber Kiyani ${ }^{2}$ \\ Sadia Paiker ${ }^{3}$
}

\author{
BDS \\ BDS, MS, FAAOMP, Dip-ABOMP \\ BDS
}

INTRODUCTION: Comprehensive head and neck examinations require sound knowledge of the population's oral anatomy, its variation, and common pathologies to distinguish between anomalous and pathological processes. Since limited data on this subject is available from Pakistan, the aim of this investigation is to determine the prevalence of oral anomalies and pathologies in healthy, Pakistani, dental patients. This will establish baseline statistics for the Pakistani population, and contribute to the international epidemiological data.

METHODOLOGY: A total of 1293 consenting, dental patients between the ages of 5-90 years underwent comprehensive head and neck examinations. Any mucosal anomaly or abnormality identified during the exam was recorded. RESULT: At least one anomaly, or abnormality was noted in $61 \%$ of the population. The most commonly documented entity was linea alba $(29.8 \%, \mathrm{n}=324)$, followed by benign oral pigmentation $(11.3 \%, \mathrm{n}=146)$, coated tongue $(5.7 \%, \mathrm{n}=74)$, prominent papillae in $(5.1 \%, \mathrm{n}=71)$, fissured tongue $(5 \%, \mathrm{n}=65)$, varicosities $(4.8 \%, \mathrm{n}=62)$, ulcers in $(4 \%, \mathrm{n}=52)$, Fordyce's granules $(2.5 \%, \mathrm{n}=32)$ and white patches $(1.8 \%, \mathrm{n}=23)$.

CONCLUSION: It is essential for dental professionals to be familiarized with the anatomical variations of the oral cavity, oral anomalies and common pathological processes to avoid misdiagnosis and prevent undue distress to the patient. KEY WORDS: Oral anomalies, oral pathologies, oral abnormalities.

HOW TO CITE: Shahzad A, Khiyani A, Paiker S. Prevalence of oral anomalies and pathologies in the pakistani population - a cross sectional study. J Pak Dent Assoc 2018;27(1):13-17.

DOI: https://doi.org/10.25301/JPDA.271.13

Received: 13 October, 2017, Accepted: 10 December, 2017

\section{INTRODUCTION}

A comprehensive oral examination is an essential aspect of a dentist's exam. It allows dentists to identify, diagnose and manage pathological conditions affecting the oral region. Conduction of thorough head and neck examination needs a sound foundation of normal anatomical structures in the region and competence to identify unusual presentations. Since anomalous presentations may appear pathological to an untrained eye, one of the key role of the dentist is distinguish between the two and prevent misdiagnosis. ${ }^{1,2}$

The prevalence of oral anomalies and pathologies has shown significant geographic variation, from reports ranging between $9.7 \%$ in Malaysian studies to as high as $81.3 \%$ in Italian investigations. ${ }^{3,4}$ Epidemiological data on prevalence of oral anomalies and pathologies from Pakistan is extremely limited. Only two studies have attempted to determine the prevalence of oral lesions in the Pakistani population. However, these studies are restricted by the type of lesion

1. Demonstrator Oral Medicine Department. Riphah International University.

2. Assistant Professor Oral Medicine Department, Riphah International University

3. PG Trainee Oral Medicine Department. Fauji Foundation University.

Corresponding author: "Dr. Ambreen Shahzad" < ambshazi@hotmail.com > being investigated, or the medical status of the patient. ${ }^{5,6}$

The aim of this investigation was to determine the prevalence of oral anomalies and pathologies in healthy Pakistani patients that are seen in the university clinics for routine dental work. Details from the extra oral examination were also included for completeness. We believe that these results will help in establishing baseline statistics for the Pakistani population, highlight the geographical variation of this region, and contribute to the international epidemiological data in this avenue. We also want to enforce the need to clinically train dental professionals to identify these common entities accurately, so appropriate management can be provided.

\section{METHODOLOGY}

This study was approved by the institution review board at Riphah International University (IIDC/IRC/2015/04/001). A cross-sectional study design was used to determine the prevalence of oral anomalies and pathologies in asymptomatic dental patients in Islamabad, Pakistan. Data was collected by consenting patients seen at the dental screening clinics at a tertiary dental care hospital from May to August 2015. 
World Health Organization sample size calculator was used to calculate the sample size:

$$
\frac{\mathrm{n}=\mathrm{Z} 2 * \mathrm{P} *(1-\mathrm{P})}{\mathrm{d} 2}
$$

Where; $\mathrm{n}=$ sample size

$\mathrm{Z}=\mathrm{Z}$ statistics for confidence level (99\% or 2.85 )

$\mathrm{P}=$ Expected prevalence or proportion $(61.8 \%)$ $\mathrm{d}=$ Precision $(5 \%$ or 0.05$)$

The expected prevalence $(61.8 \%)$ was taken from a study conducted in North India. ${ }^{7}$ The sample size was calculated to be 629 . A total of 1293 randomly selected individuals between the ages of 5-90 years were enrolled in the study. It was ensured that the patient's chief complaint was a dental problem. Any patient coming in with a complaint of oral mucosal problem was excluded from this investigation.

Two general dentists were trained by an oral medicine expert to perform comprehensive head and neck examinations on each participant using a light source, dental mirror, and a piece of gauze for the tongue. Their competence at identifying anomalous and pathological processes in the oral cavity was assessed by the clinical oral pathologist and the oral medicine expert before the initiation of the study.

The dentists performed comprehensive oral exams on consenting patients on the dental units in the out-patient clinics. Records were made of any anomaly or pathology noted on the buccal, labial, palatal, lingual, sublingual and gingival mucosae. Anomalies of teeth, if any, were also recorded. Details of caries, filled and missing teeth were not noted. Positive findings along with the patient's demographic details were transferred on to a data sheet; all identifiable information was discarded after this step.

The data was analysed using SPSS version 20. Descriptive statistics were used to calculate the prevalence of individual anomalies and pathologies. Cross-tabs were used to compare the prevalence of common anomalies between males and females and among different age groups.

\section{RESULTS}

Out of the 1293 patients examined, $52.7 \%(\mathrm{n}=681)$ were male and $47.3 \%(n=612)$ were female. The mean age range of patients seen in the screening clinics was 21-30 years; $25.1 \%(\mathrm{n}=324)$ with a standard deviation of +1.65 . About $61 \%(\mathrm{n}=786)$ of patients had at least one anomaly.

Linea alba was noted in $29.8 \%(\mathrm{n}=324)$ (figure 1), ethnic or physiological pigmentation in $11.3 \%(n=146)$ (figure 2), coated tongue in $5.7 \%(\mathrm{n}=74)$ (figure 3$)$, prominent papillae in $5.1 \%(n=71)$, fissured tongue in $5 \%(n=65)$ (figure 4$)$, varicosities in $4.8 \%(n=62)$, ulcers in $4 \%(n=52)$, attrition $2.9 \%(n=37)$, Fordyce's granules in $2.5 \%(n=32)$, dental abscess in $2.5 \%(n=32)$, white patch in $1.8 \%(n=23)$,

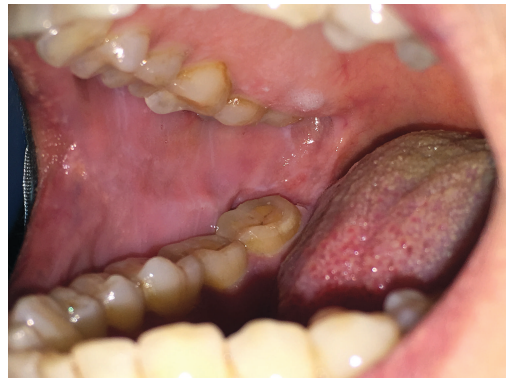

Fig:1

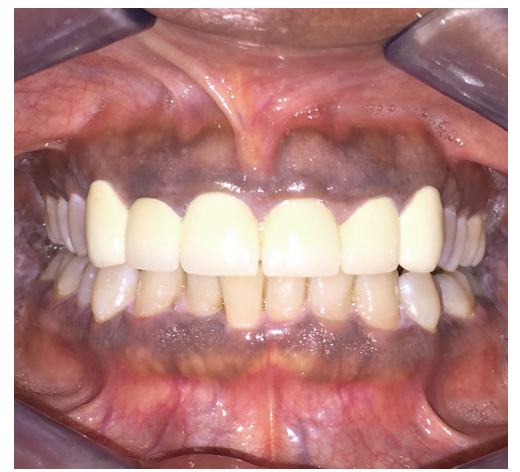

Fig:2

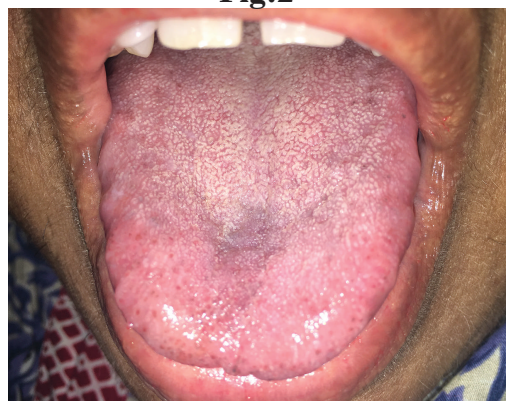

Fig:3

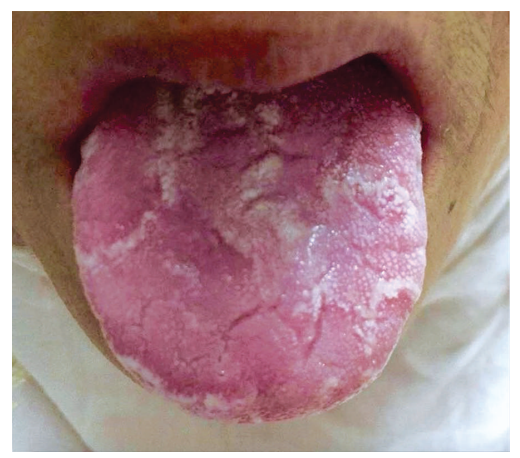

Fig:4

xerostomia in $1.4 \%(n=18)$, and "others" in less than $1 \%$.

The "others" category lumped up entities like abrasion $(0.8 \%, \mathrm{n}=10)$, tori and fungal infection $(0.6 \%, \mathrm{n}=7)$, abfraction $(0.5 \%, \mathrm{n}=6)$, fluorosis $(0.4 \%, \mathrm{n}=5)$, and amalgam tattoo $(0.3 \%, n=4)$. It also included haemangioma, median rhomboid glossitis, inflammatory fibrous hyperplasia, tooth anomalies, mucocele and geographic tongue (figure 4), each of which 
were identified in $0.2 \%(n=3)$ of the sample. Oral submucous fibrosis, lichen planus, pyogenic granuloma and chemical burns were noted in $0.2 \%(n=2)$ of the population while scarred tongue and sebaceous cyst were seen in $0.1 \%(n=1)$.

Linea alba was more frequently noted in females, $30.4 \%$ $(n=186)$ vs $29.2 \%(n=199)$ in males. Fissured tongue also showed a female predilection, $5.2 \%(n=32)$ vs $4.85 \%(n=33)$ in males. Benign oral pigmentation, arcus senilis, varicosities and nevi were more common in males $(12.04 \%, \mathrm{n}=82$ : $11.4 \%, \mathrm{n}=78: 5.1 \%, \mathrm{n}=35$ and $10.4 \%, \mathrm{n}=71$ respectively) as compared to females $(10.5 \%, \mathrm{n}=64: 7.35 \%, \mathrm{n}=45: 4.6 \%$, $\mathrm{n}=28$ and $9.6 \%, \mathrm{n}=55$ respectively). (Table 1 )

\begin{tabular}{|c|c|c|c|c|c|c|}
\hline LESIONS & $\begin{array}{l}\text { Males } \\
\text { (\%) }\end{array}$ & $\begin{array}{l}\text { Males } \\
\text { (n) }\end{array}$ & $\begin{array}{l}\text { Females } \\
\text { (\%) }\end{array}$ & $\begin{array}{l}\text { Females } \\
\text { (n) }\end{array}$ & $\begin{array}{l}\text { Total } \\
(\% *)\end{array}$ & $\begin{array}{l}\text { Total } \\
\text { (N) }\end{array}$ \\
\hline INTRA ORAL & & & & & & \\
\hline Linea Alba & 29.2 & 199 & 30.4 & 186 & 29.8 & 385 \\
\hline $\begin{array}{l}\text { Benign Oral } \\
\text { Pigmentation }\end{array}$ & 12 & 82 & 10.5 & 64 & 11.3 & 146 \\
\hline Coated Tongue & 6.3 & 43 & 5 & 31 & 5.7 & 74 \\
\hline Prominent Papilla & 5.4 & 37 & 5.6 & 34 & 5.1 & 71 \\
\hline Fissured Tongue & 4.9 & 33 & 5.2 & 32 & 5 & 65 \\
\hline Varicosities & 5.1 & 35 & 4.6 & 28 & 4.8 & 62 \\
\hline Ulcers & 3.8 & 26 & 4.2 & 26 & 4 & 52 \\
\hline Attrition & 2.8 & 19 & 2.9 & 18 & 2.9 & 37 \\
\hline Fordyce's Granules & 3.8 & 26 & 0.98 & 6 & 2.5 & 32 \\
\hline Dental Abscess & 2.6 & 18 & 2.3 & 14 & 2.5 & 32 \\
\hline White Patch & 2.3 & 16 & 1.1 & 7 & 1.8 & 23 \\
\hline Dry Mouth & 0.4 & 3 & 2.5 & 15 & 1.4 & 18 \\
\hline
\end{tabular}

\begin{tabular}{lcccccc} 
Nevi & 10.4 & 71 & 9.6 & 55 & 9.7 & 126 \\
\hline Arcus Senilis & 11.4 & 78 & 9.4 & 45 & 9.4 & 122 \\
\hline Pinguecula & 1.6 & 11 & 0.3 & 2 & 1 & 13 \\
\hline
\end{tabular}

Table: 1 Showing the frequency and percentages of some oral anomalies and abnormalities, and their distribution among male and female patients, where " $n$ " in the frequency of the lesion in either male or female, "N" is the total number of a particular anomaly, "\%" is the percentage of an anomaly in either males or females and "\%*" is the total percentage of lesions.

Linea alba was most commonly observed in the age group 31-40 years (35\%) followed by $41-50$ years (33.7\%) and $21-30$ years $(33.02 \%)$. Fissured tongue was seen in the age groups $61-70$ years $(12.5 \%), 51-60$ years $(12 \%)$ and $71-$
80 years $(11.76 \%)$. Varicosities were also seen in the elderly population, $71-80$ years (17.6\%), followed by $61-70$ years $(14 \%)$ and $51-60$ years $(7.8 \%)$.

\section{DISCUSSION}

According to our investigation, $60.8 \%$ of the population presented with at least one oral anomaly. This is in close proximity with the investigations performed in Italy $81.3 \%$, Yemen $77.1 \%$, Brazil $73.4 \%$, North India $61.8 \%$, Slovenia $61.6 \%$, Kuwait $58.1 \%$ and South India $41.2 \% .^{3,7-13}$ It is significantly higher than reports from Iran $19.4 \%$, Turkey $15.5 \%$, Saudi Arabia $15 \%$, China $10.8 \%$, USA $10 \%$, and Malaysia $9.7 \% .^{4,14-18}$

While linea alba was the most prevalent anomaly identified in our population and in Turkish studies, the results from other countries are quite variable. ${ }^{15}$ Coated tongue was the most common oral anomaly identified in Italian men (51\%), Fordyce granules in the Slovenian population $49.7 \%$, fissured tongue in the Brazilian-Indian population and lingual varicosities in the older individuals of Thailand. . $^{3,9,10,13}$

The more frequently encountered oral, and extra oral anomalies and pathologies are described under individual headings below.

\section{Linea Alba:}

Linea Alba was observed in $29.8 \%(\mathrm{n}=324)$ of the population. We believe that this can be attributed to the diet and habits of the Pakistani population. Our results are comparable to the North Indian population (22.2\%) that consumes a similar diet and exhibits similar habits. Similar to our results, the North Indian study also reported a higher prevalence in females. ${ }^{7}$ Our results are significantly higher than other populations that consume much softer diets; Kuwait 11.4\%, Turkey $4.2 \%$, and Slovenia. ${ }^{10,11,15}$

\section{Fissured tongue:}

Fissured tongue was seen in 5\% of the population, and it was more common in females $(5.2 \%, \mathrm{n}=32)$ in comparison to males $(4.85 \%, \mathrm{n}=33)$. The prevalence from Thailand $(28 \%)$, and Slovenia (21\%) is much higher than what was noted in our population. ${ }^{10,13}$ It was more comparable to the results yielding from South India (5.7\%), Iran (4\%), and China (3.2\%). ${ }^{12,17,19}$ The percentage was however significantly higher than the Saudi population. ${ }^{16}$ The reasons for discrepancy in results in not known.

\section{Ethnic or Physiological Pigmentation:}

Physiological or racial oral pigmentation was noted in $11.3 \%$ of the Pakistani population. This can be attributed 
to the higher amount of melanin expression in the skin and mucus membranes. ${ }^{1}$ The results from the slightly darker population of North India were $29.9 \%$, while those from fairer populations were significantly lower than our results; Iran $2.5 \%$, Saudi Arabia 0.6\% and Turkey 0.5\%.,14-16

\section{Coated tongue:}

About $12 \%$ of the patients in our study had coated tongues. This frequency is lower than the reports from Italy $51.4 \%$ and India $28 \%{ }^{3,20}$ but much higher than Turkish population $2.1 \% .{ }^{15}$ This variation may have resulted from the diets consumed by respective populations.

\section{Fordyce's Granules:}

We recorded Fordyce's granules in $2.5 \%(n=32)$ of the population. Our results were significantly lower than those noted in the Slovenian $49.7 \%$ and Kuwaiti $20 \%$ population; however they were similar to the results from South India 6.55\%, Saudi Arabia 3.8\%, Turkey $2.8 \%$, Iran $2.8 \% .^{10-12,14-16}$

\section{Lingual Varices:}

We found lingual varices in $4.8 \%(n=62)$ of the population. Most of the individuals with varices were in the elderly category; $17.6 \%$ in $71-80$ years, $14 \%$ in $61-70$ years, $7.8 \%$ in $51-60$ years and $5.7 \%$ in $41-50$ years. The reported incidence of $60 \%$ in the Thai population is very high in comparison to our results, possibly because their patient pool consisted of the elderly. ${ }^{13}$ Our results however are notably higher in comparison to the results yielding from Slovenia $1.6 \%$, and Iran $1.5 \% .^{10,14}$

\section{Traumatic Ulceration:}

Traumatic ulceration was noted in $4 \%(n=52)$ of our sample population. This is much lower than the reports from the elderly population of Thailand $15.6 \%$, who may exhibit a higher incidence due to denture use. Our results are somewhat comparable to the results from North India $6.1 \%$, Saudi Arabia 1.9\%, China $1.1 \%$ and $0.9 \%$ in Turkey. ${ }^{7,13,15-17}$

\section{White Lesions:}

About 3\% (n=34) of the patients presented with white lesions. While the majority of these were frictional keratosis, we had one patient with leukoplakia, $0.08 \%$ of the sample population. This is significantly lower than the $13.8 \%$ reported in Italian men, 3.1\% in Slovenians, and 1\% in South Indians. ${ }^{3,10,12}$ However, these results are consistent with the findings from China $0.2 \%$, and Iran $0.1 \% .^{14,17}$

One of the limitations of this study was sampling patients from a single institution in Pakistan. This institute may provide a good estimate for Northern Pakistan but failed to provide a proportionate representation of the rest of the country. Future studies can aim at including appropriate representation from each part of Pakistan to provide a better estimate.

\section{CONCLUSION}

Familiarity of dental professionals with anatomical variations of the oral cavity and common pathological processes is essential because the majority of the population will present with at least anomaly or pathology. This knowledge will prevent misdiagnosis and undue stress to the patient.

\section{CONTINUING EDUCATION}

\section{Which of the following is an oral anomaly?}

a) Leukoplakia

b) Aphthous ulcer

c) Fordyces granules

d) Traumatic ulcer

Correct answer (d) Fordyces granules

\section{Which of the following is the most common oral anomaly} observed in Pakistani patients?

a) Linea alba

b) Fordyces granules

c) Physiological pigmentation

d) Prominent papilla

Correct answer (a) linea alba

Lingual varices are more frequently observed in?

a) 2nd decade of life

b) 3rd decade of life

c) 4th decade of life

d) 7th decade of life

Correct answer (d) 7th decade of life

A biopsy may be indicted to diagnose?

a) Geographic tongue

b) White patch

c) Linea alba

d) Traumatic ulcer

Correct answer (b) White path

\section{CONFLICT OF INTEREST}

There is no conflict of interest.

No sources of funding were used for the study.

We certify that the presented data is accurate and can be 
made available on request.

\section{REFERENCES}

1. Jean M. Bruch, Triester NS. Varients of Normal and Common Benign Conditions. Clinical Oral Medicine and Pathology: LLC; 2010.

2. Madani FM, Kuperstein AS. Normal Variations of Oral Anatomy and Common Oral Soft Tissue Lesions. Medical Clinics.98(6):1281-98. https://doi.org/10.1016/j.mcna.2014.08.004

3. Campisi G, Margiotta V. Oral mucosal lesions and risk habits among men in an Italian study population. J Oral Pathol Med. 2001;30(1):22-8.

https://doi.org/10.1034/j.1600-0714.2001.300104.x 4. Zain RB, Ikeda N, Razak IA, Axell T, Majid ZA, Gupta PC, et al. A national epidemiological survey of oral mucosal lesions in Malaysia. Community Dent Oral Epidemiol. 1997;25(5):377-83.

https://doi.org/10.1111/j.1600-0528.1997.tb00959.x

5. Ayesha Maqsood, Nadia Aman, Chaudry MAG. Oral White Lesions: Presentation and Comparison of Oral Submucous Fibrosis with Other Lesions. J Coll Physicians Surg Pak. 2013;23(12):870-3.

6. Saeeda Baig, Mohammad Haris Lucky, Areeba Qamar, Farah Ahmad, Shaji Khan, Waqas Ahmed, et al. Human Papilloma Virus and Oral Lesions in Gutka Eating Subjects in Karachi. J Coll Physicians Surg Pak. 2012;22(3):135-8. 7. Patil S, Yadav N, Patil P, Kaswan S. Prevalence and the relationship of oral mucosal lesions in tobacco users and denture wearers in the North Indian population. J Family Community Med. 2013;20(3):187-91.

https://doi.org/10.4103/2230-8229.122009

8. Al-Maweri SA, Al-Jamaei AA, Al-Sufyani GA, Tarakji B, Shugaa-Addin B. Oral mucosal lesions in elderly dental patients in Sana'a, Yemen. Journal of International Society of Preventive \& Community Dentistry. 2015;5(Suppl 1):S129.

https://doi.org/10.4103/2231-0762.156152

9. dos Santos PJ, Bessa CF, de Aguiar MC, do Carmo MA. Cross-sectional study of oral mucosal conditions among a central Amazonian Indian community, Brazil. J Oral Pathol Med. 2004;33(1):7-12.

https://doi.org/10.1111/j.1600-0714.2004.00003.x

10. Kovac-Kovacic M, Skaleric U. The prevalence of oral mucosal lesions in a population in Ljubljana, Slovenia. $\mathbf{J}$ Oral Pathol Med. 2000;29(7):331-5.

https://doi.org/10.1034/j.1600-0714.2000.290707.x

11. Ali M, Joseph B, Sundaram D. Prevalence of oral mucosal lesions in patients of the Kuwait University Dental Center.
The Saudi dental journal. 2013;25(3):111-8. https://doi.org/10.1016/j.sdentj.2013.05.003

12. Mathew AL, Pai KM, Sholapurkar AA, Vengal M. The prevalence of oral mucosal lesions in patients visiting a dental school in Southern India. Indian J Dent Res. 2008;19(2):99-103.

https://doi.org/10.4103/0970-9290.40461

13. Jainkittivong A, Aneksuk V, Langlais RP. Oral mucosal conditions in elderly dental patients. Oral Dis. 2002;8(4):21823.

https://doi.org/10.1034/j.1601-0825.2002.01789.x

14. Mansour Ghanaei F, Joukar F, Rabiei M, Dadashzadeh A, Kord Valeshabad A. Prevalence of oral mucosal lesions in an adult Iranian population. Iranian Red Crescent medical journal. 2013;15(7):600-4.

https://doi.org/10.5812/ircmj.4608

15. Cebeci AR, Gulsahi A, Kamburoglu K, Orhan BK, Oztas B. Prevalence and distribution of oral mucosal lesions in an adult Turkish population. Med Oral Patol Oral Cir Bucal. 2009;14(6):E272-7.

16. Al-Mobeeriek A, AlDosari AM. Prevalence of oral lesions among Saudi dental patients. Ann Saudi Med. 2009;29(5):3658.

https://doi.org/10.4103/0256-4947.55166

17. Feng J, Zhou Z, Shen X, Wang Y, Shi L, Wang Y, et al. Prevalence and distribution of oral mucosal lesions: a crosssectional study in Shanghai, China. J Oral Pathol Med. 2015;44(7):490-4.

https://doi.org/10.1111/jop.12264

18. Bouquot JE. Common oral lesions found during a mass screening examination. J Am Dent Assoc. 1986;112(1):507.

https://doi.org/10.14219/jada.archive.1986.0007

19. Fotouhi A, Hashemi H, Khabazkhoob M, Mohammad $\mathrm{K}$. Prevalence and risk factors of pterygium and pinguecula: the Tehran Eye Study. Eye (London, England). 2009;23(5):1125-9.

https://doi.org/10.1038/eye.2008.200

20. Patil S, Kaswan S, Rahman F, Doni B. Prevalence of tongue lesions in the Indian population. Journal of clinical and experimental dentistry. 2013;5(3):e128-32. https://doi.org/10.4317/jced.51102

21. Raj KM, Reddy PA, Kumar VC. Significance of corneal arcus. J Pharm Bioallied Sci. 2015;7(Suppl 1):S14-5. https://doi.org/10.4103/0975-7406.155765

22. Fernandez AB, Keyes MJ, Pencina M, D'Agostino R, O'Donnell CJ, Thompson PD. Relation of corneal arcus to cardiovascular disease (from the Framingham Heart Study data set). Am J Cardiol. 2009;103(1):64-6.

https://doi.org/10.1016/j.amjcard.2008.08.030 